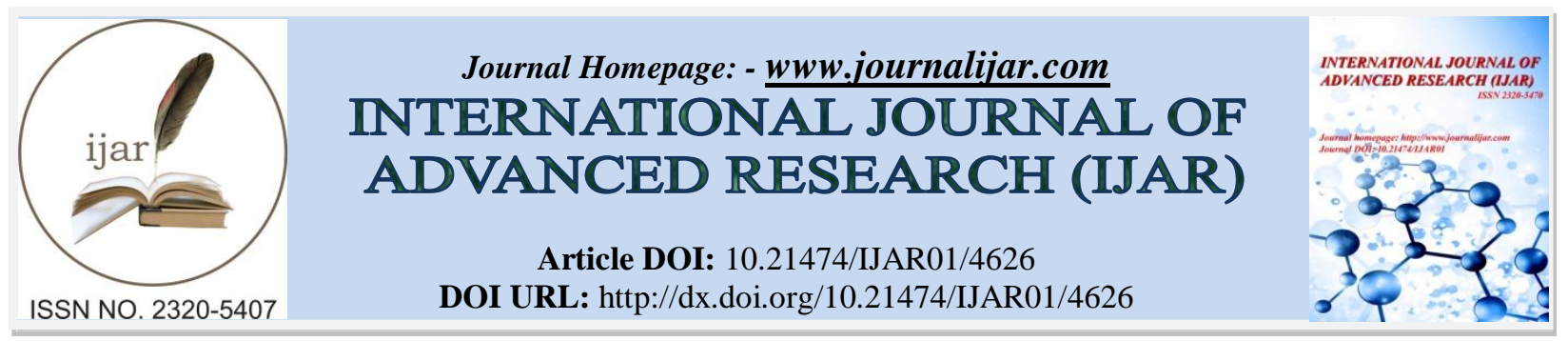

RESEARCH ARTICLE

\title{
ASSESSMENT OF KNOWLEDGE, ATTITUDE, AND PRACTICE (KAP) OF CERVICAL CANCER AND SCREENING AMONG ADULT ARMY WOMEN AGED 18 YEARS AND ABOVE IN ADDIS ABABA, ETHIOPIA.
}

Shewaye Haile Shibeshi and Mebrate Degefu.

Tongji University, College of Medicine; Siping Road, 1239, Shanghai, China.

\section{Manuscript Info}

........................

\section{Manuscript History}

Received: 27 April 2017

Final Accepted: 29 May 2017

Published: June 2017

\section{Abstract}

Background: Cervical cancer is one of the gravest threats to women's lives. It is estimated that over a million women worldwide currently suffer from cervical cancer. Most of these women have neither been diagnosed, nor do they have access to treatment that could cure them or prolong their lives. Public and individual awareness can play a vital role in the prevention, early diagnosis and treatment of cervical cancer.

Objectives: To assess the knowledge, Attitude, and Practice of cervical cancer and Screening among army women aged 18 and above years in Addis Ababa

Methods: A cross-sectional descriptive study design was conducted among 346 army women aged 18 years and above. The study subjects were selected from different military camps by stratified sampling. Data were entered into EPI info version 3.5.1 and exported to SPSS version 20 for analysis. Frequencies, proportions and summary statistics were used to describe the study population in relation to relevant variables. The impact of selected socio- demographic and other characteristics on knowledge, Attitude, Practices of cervical cancer was investigated using both bivariate method and multivariate logistic regression techniques.

Results: The majority $328(94.7 \%)$ of the study participants had heard about cervical cancer and screening and $302(87.3 \%)$ about cervical cancer smear. Almost two-third $225(65 \%)$ of respondents were Knowledgeable and 217(62.7\%) had positive attitude towards cervical cancer screening. Three hundred twenty $(92.48 \%)$ participants were not screened for cervical cancer and only $7.5 \%$ were screened in their lifetime. When asked reasons for not being screened, half (56.6\%) said they were healthy and about $77\left(24.6^{\circ} \%\right)$ said that they didn't have information. In

Multivariate analysis those who were older were 7 time knowledgeable than younger age groups $(\mathrm{AOR}=\mathbf{7 . 3 6}$; $95 \% \mathrm{CI}=\mathbf{1 . 8 0}$ 30.02) and rank officers nearly 4 time Knowledgeable than Nonofficer Army women. $(\mathrm{AOR}=\mathbf{3 . 9 2}$; 95\% CI $=\mathbf{1 . 6 1 - 9 . 5 5})$

Conclusion: The present study concludes that there is satisfactory knowledge and Attitude among female army about cervical cancer and screening .Nevertheless, the screening uptake is low, the need for 
more advocacy work by service provider to measure the necessary practice.

Copy Right, IJAR, 2017,. All rights reserved.

\section{Introduction:-}

Cervical cancer is one of the gravest threats to women's lives. It is estimated that over a million women worldwide currently have cervical cancer (1). Most of these women have not been diagnosed, nor do they have access to treatment that could cure them or prolong their lives. In 2012, 528000 new cases of cervical cancer were diagnosed, and 266000 women died of the disease and nearly $90 \%$ of them were from low- and middle-income countries (1). Without due attention, deaths due to cervical cancer are projected to rise by almost $25 \%$ over the next 10 years .Cervical cancer occurs worldwide, but the highest incidence rates are found in Central and South America, East Africa, South and South-East Asia, and the Western Pacific. Over the past three decades, cervical cancer rates have fallen in most of the developed world, largely as a result of screening and treatment program(1). In contrast, rates in most developing countries have risen or remained unchanged. Major disparities also exist in the developed world, where rural and poorer women are at greatest risk of invasive cervical cancer $(1,13)$.

In sub-Saharan Africa, 34.8 new cases of cervical cancer are diagnosed per 100, 000 women annually, and 22.5 per 100000 women die from the disease (2). These figures compare with 6.6 new cases and 2.5 women die from the disease per 100, 000 women, respectively in North America $(2,12)$. The drastic differences can be explained by lack of access to effective screening and to services that facilitate early detection and treatment (2). Cervical cancer remains the most common malignancy among women in Ethiopia (2). In 2012, the estimated age standardized incidence and mortality rates were 26.4 and 18.4 per 100,000 , respectively corresponding to a four and nine times higher incidence and mortality rate than in Western Europe $(3,15)$. Eastern Africa, about $4.7 \%$ of women in the general population are estimated to harbor cervical HPV-16/18 infection at a given time and $68.3 \%$ of invasive cervical cancers are attributed to HPVs 16 or $18(4,14)$.One major determinant for the prognosis of cervical cancer is the stage at which the patient presents(5). Most patients in developing countries, including Ethiopia present late with advanced stage disease, in which treatment may often involve multiple modalities 2 including surgery, radiotherapy, chemotherapy, and has a markedly diminished chance of success (5 \& 17).

Several factors such as educational status, financial capability, location, presence of health care facilities determine the stage at which patients with cancer present in the health facility. However, a common denominator of these factors is the level of awareness and attitude patients have about the diseases $(6,16)$. There is an increased chance of presenting early for treatment if patients have awareness about the disease (7).

Most women who die from cervical cancer, particularly in developing countries, are in the prime of their lives (1). They may be raising children, caring for their families and contributing to the social and economic lives of their towns and villages. A woman's death is both a personal tragedy and a sad and unnecessary loss to her family and her community, with enormous repercussions for the welfare of both (1). These deaths are unnecessary because there is compelling evidence that cervical cancer is one of the most preventable and treatable forms of cancer if it is detected early and managed effectively (1). While less developed countries are clearly more likely to lack effective health systems and adequate financial resources compared with developed countries, it is crucial to underscore that another of the most overlooked but powerful drivers of cervical cancer is a lack of equality for women in terms of access to health care in many societies(1).

\section{Materials and Methods:-}

\section{Study Area:-}

The study was conducted in Military Camps of Addis Ababa, Ethiopia. Addis Ababa is the Capital City of Ethiopia as well as the seat of the African Union and different international offices. It covers an estimated area of 174.4 square kilometers with an estimated density of 5,535.8 people per square kilometer (34). Based on the 2007 census of the Central Statistical Agency of Ethiopia, the total population of Addis Ababa for the year 2014 was about 3.55 million with the proportion of male and female being $49 \%$ and $51 \%$, respectively. The number of females in reproductive age group constitutes $35.5 \%$ among the total population (34). This study area was selected because of large female military personnel compared to other cities. Women army members of the Ministry of National Defense Force live in more than ten different camps in Addis Ababa. Three camps namely: Feresegna, Signal higher 
officer's and Gofa Camps were selected randomly, where Feresegna and Signal Camp are situated in Yeka sub-city and Gofa camp is situated in Nefasselk- Lafto sub-city, Eastern part of Addis Ababa.

\section{Sample Size Determination:-}

A single population proportion formula, $[\mathrm{n}=(\mathrm{Z} \mathrm{a} / 2) 2 \mathrm{p}(1-\mathrm{p}) / \mathrm{d} 2]$, was used to estimate the sample size of women to be interviewed. The following assumptions have been made: proportion of women having knowledge about cervical cancer was 31\% from the previous study (24), with 95\% confidence level, and margin of error at 5\% $(\alpha=0.05)$ and $5 \%$ non-response rate.

\section{$\mathbf{N}=\frac{\mathbf{Z}^{2} \times \mathbf{P}(\mathbf{1}-\mathbf{P})}{\varepsilon^{2}}$}

Where;

$\mathrm{n}=$ required sample size

$\mathrm{Z}=$ reliability coefficient at $95 \%$ confidence level (standard value of 1.96 )

$\mathrm{p}=$ proportion of population with characteristics of interest

$\varepsilon=$ margin of error at $5 \%$ (standard value of 0.05 )

$\mathrm{n}=(1.96) 2 * .31 * .69=328.68=329$

$(.05) 2$

$329+5 \%$ Non-respondent rate $(17)=346$

\section{Data Analysis:-}

The data was entered in to EPI info and exported to SPSS version 20 software. Data cleaning was performed to check for accuracy, consistency and missed values. Frequencies, proportions and summary statistics were used to describe the study population in relation to relevant variables.

\section{Results:-}

\section{Socio- demographic characteristics of the study population}

All the recruited 346 participants' response to questionnaires making the respondent rate $100 \% ; 157$ (45.3\%) of participants were greater than 37 years of age. The mean age of the participants was $33.9( \pm 7.4)$. The majority $(82.71 \%)$ were Orthodox followed by others Christians which accounts for 46(13.03\%) and Muslim 14(4\%). about two-thirds of respondent $(71.7 \%)$ attended tertiary level of education .More than two-thirds (78\%) were currently married and over half of the respondents are (51.4\%) women army are non-officers; and 255(73.7\%) of the women had a parity of 1-4. (Table1).

Table 1:- Percentage distribution of the female army members by socio-demographic characteristics, Addis Ababa Ethiopia, 2016

\begin{tabular}{|c|c|c|}
\hline Variables & Frequency & Percent \\
\hline Age & & 17.1 \\
\hline $19-24$ years & 59 & 28.9 \\
\hline $25-30$ years & 100 & 8.7 \\
\hline $31-36$ years & 30 & 45.3 \\
\hline$>37$ years & 157 & \\
\hline Mean \pm SD $)=33 . \pm 7.4$ & & 82.7 \\
\hline Religion & 286 & 43.30 \\
\hline Orthodox & 46 & 4 \\
\hline Other Christine & 14 & .6 \\
\hline Muslim & & 20.8 \\
\hline Educational Status & 2 & 71.67 \\
\hline primary school & 72 & 6.93 \\
\hline secondary school & 248 & 78.03 \\
\hline Tertiary & 24 & 21.97 \\
\hline University & 270 & \\
\hline Marital union & 76 & \\
\hline yes & & \\
\hline No & & \\
\hline Husband education & & \\
\hline
\end{tabular}




\begin{tabular}{|c|c|c|}
\hline Primary school & - & - \\
\hline Secondary school & 44 & 16.29 \\
\hline Tertiary & 122 & 45.19 \\
\hline University & 104 & 38.52 \\
\hline Rank & & 51.4 \\
\hline Non-officer & 178 & 48.6 \\
\hline Officer & 168 & \\
\hline Parity & & 26.3 \\
\hline Nulliparous & 91 & 73.7 \\
\hline 1-4 Children & 255 & \\
\hline
\end{tabular}

\section{Knowledge of women on cervical cancer and screening:-}

The overall respondent's knowledge towards cervical cancer and its screening were categorized as Knowledgeable and not Knowledgeable using the mean score of the respondents on the knowledge part questions; The mean knowledge score was 10.74 ( $\mathrm{SD} \pm 1.97$ ) above the mean score considered knowledgeable, the minimum knowledge score was 2 and Maximum score was 16 . About two-third (65\%) of the respondents were Knowledgeable. Majority $(87.3 \%)$ heard about cervical cancer smear and $44(12.7 \%)$ not heard.

\section{Source of information:-}

The majority $(94.7 \%)$ of the respondents had heard about cervical cancer and screening. When they were asked about the source of information, mass media was the predominant source; $234(67.6 \%)$ followed by health professionals $122(35.2 \%)$ and friends/relatives $45(13 \%)$ with those who did not hear any information $18(5.2 \%)$. (Figure 1)

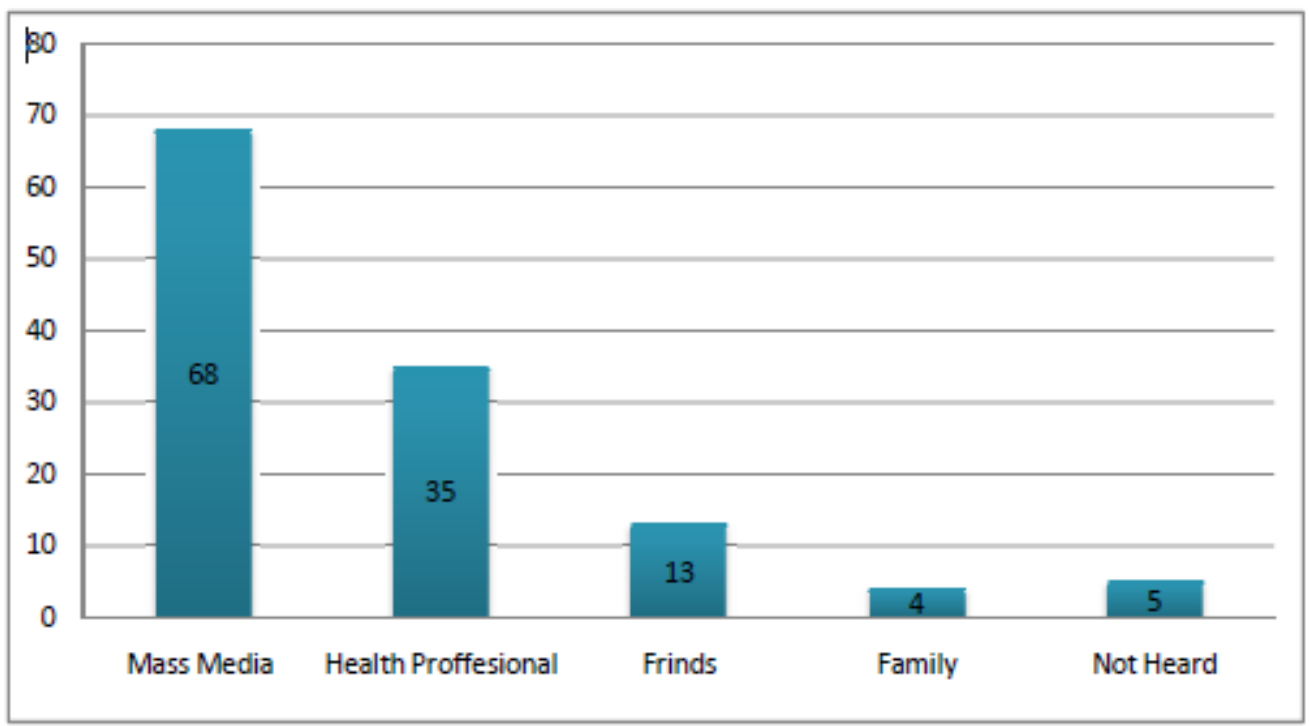

Figure 1:- Source of information on cervical cancer of female army members in Addis Ababa, Ethiopia, 2016 Note: Due to multiple responses, sum of percentages $>100$

\section{Attitude:-}

A total of five questions were put on Liker's scale to assess the attitude of participants towards cervical cancer screening. The minimum and maximum scored on the attitude questions by the respondents were 5 and 25 respectively. Two hundred seventy $(62.7 \%)$ the respondents had positive attitude towards cervical cancer screening. while the rest 129(37.3\%) had negative attitude. Almost all (96.9\%) of the respondents agreed that carcinoma of the cervix is the common causes of death in our country; 297 (85.9\%) perceived that any woman can acquire cervical cancer. About two-third (65.02\%) agreed that cervical cancer is not transmitted from female to female and half $(50.9 \%)$ of the agreed the procedure cannot cause any harm and 390(92.19\%) agreed screening helps in the prevention of cervical cancer; (Table: 2 ) 
Table 2:- Attitude of respondent toward cervical cancer screening army in A.A, 2016.

\begin{tabular}{|c|c|c|}
\hline Variable & Frequency & Percent \\
\hline Carcinoma of cervix is cause of death & & 37.3 \\
\hline Strongly agree & 129 & 59.6 \\
\hline Agree & 206 & 1.4 \\
\hline Neither agree nor Disagree & 5 & 1.7 \\
\hline Disagree & 6 & 14.5 \\
\hline Any woman acquires cervical cancer & 50 & 71.4 \\
\hline Strongly agree & 247 & 2.9 \\
\hline Agree & 10 & 11.3 \\
\hline Neither agree nor disagree & 39 & 2 \\
\hline Disagree & & 63 \\
\hline Carcinoma of the cervix cannot be & 7 & 17.92 \\
\hline Strongly agree & 218 & 17.05 \\
\hline Agree & 62 & 11 \\
\hline Neither agree nor disagree & 59 & 39.9 \\
\hline Disagree & & 23.3 \\
\hline Screening causes no harm to the client & 38 & 24.6 \\
\hline Strongly agree & 138 & \\
\hline Agree & 85 & 46.3 \\
\hline Neither agree nor disagree & 82 & 46 \\
\hline Disagree & & 4.9 \\
\hline Strongly agree & 160 & 2.6 \\
\hline Agree & 159 & 17 \\
\hline Disagree & 9 & \\
\hline
\end{tabular}

\section{Discussion:-}

\section{Knowledge:-}

This study was conducted to assess the knowledge, attitude, practice of cervical cancer and screening among female army members in Addis Ababa. The findings from this research showed that majority of the female had heard about cervical cancer and heard about cervical cancer screening. When they were asked about the source of information, mass media was the predominant source followed by health professionals and friends/relatives. This seems somehow to be higher than those with a similar study done in Gondar Town, Northwest Ethiopia, which reported about $78.7 \%$ of the respondents had heard about cervical cancer (24). This indicates that media can play an important role in educating women regarding cervical cancer. Medias like radio and TV are these days accessible in many households and information can simply reach to the wide community without any additional cost. Contrary to this, a study done in Kenya reported that, the main sources of information were health care providers (35) and in Addis Ababa 2008, the main source of information was health institutions (36). The difference could be due to the study subjects and the study period and the place where the study were conducted.

Concerning prevention of cervical cancer, the majority in this study knew that cervical cancer could be prevented by avoiding multiple sexual partners, avoiding early sexual intercourse and by quitting smoking. While in a study done in Sweden reported that $62 \%$ of cervical cancer can be prevented by early screening and HPV vaccination (37). This disparity may be due to study setting in that the service mentioned the developed nations like Sweden, early screening and availability of HPV vaccination are available widely and affordable for most of the population .

The overall knowledge of participants on factors contributing to cervical cancer are low and the most common factors mentioned were multiple sexual partners, early sexual intercourse and smoking. This study agrees with study done in Cameroon, which documented that multiple sexual partners as common factor (22). There were also respondents who did not known about HPV infection and its link to cervical cancer. In this study in contrary to the Nigerian study showed that (87.7\%); of the study subjects correctly identified HPV as the primary cause of cervical cancer (38). Regarding the respondents' knowledge of the main symptoms of cervical cancer, only $41.42 \%$ of them 
identified, Vaginal foul smelling and Vaginal bleeding as the common symptoms and few did not know any symptoms of cervical cancer and the present finding is lower than the study done in Yemen which reported that $61.7 \%$ had knowledge about the clinical picture of cervical cancer (39). Understanding the need for more promoted health education activities aiming on early detection is more important.

Regarding treatment of cervical cancer majority mentioned that cervical cancer is treatable when discovered early and correctly mentioned the treatment methods which included Chemotherapy, Radiotherapy and Surgical treatment. And the finding is concordant with study done in Yemen(40) The majority of females with this study thought that cervical cancer could be treated by Surgical treatment (35.6\%) followed by Chemical therapy (34.1\%), while only a few were aware of radiotherapy (6.1\%) as a treatment option (39). In contrast to Tanzania study radiotherapy was mentioned the most common (70.8\%) form of treatment identified, followed by surgery (32.1\%) and chemotherapy $(23.4 \%)(40)$.

\section{Attitude:-}

This study also looked at the respondent's attitude on cervical cancer screening. Overall, more than half of the respondents had a positive attitude towards cervical cancer screening. Almost all agreed that carcinoma of the cervix is the common cause of death in our country. Majority of the respondents perceived that any woman can acquire cervical cancer and also agreed that screening is an important method of prevention .The finding is higher than the study done in Dessie reported that good attitude 42.1\% (41) and lower than the Iran finding of 95\%. (42).The difference may be due to the socio economic difference and knowledge level between the two countries. This study found out that level of knowledge of cervical carcinoma was associated with positive attitude, but not with practice of screening.

\section{Conclusion:-}

This study concludes that there is satisfactory knowledge and attitude among female army members about cervical cancer and screening, but uptake of screening services for cervical cancer is minimal. The awareness of cervical cancer screening among the respondents was moderate but their knowledge of the signs and symptoms and risk factors associated with cervical cancer was low. This indicates that the women have a high level of the general knowledge about the disease but limited knowledge of the disease itself or its progression. Screening uptake was very low despite the high levels of awareness of cervical cancer and cervical cancer screening. This indicates that there is disconnect between the respondents awareness and their health seeking behavior with regards to cervical cancer and screening.

A major barrier to screening was little or no understanding of the disease as well as lack of information about cervical cancer and screening itself. Many women also reported that they did not feel at risk and others stated that they didn't have information. At the same time awareness of cervical cancer, awareness of cervical cancer screening and knowledge of modes of prevention of cervical cancer were found critical in determining cervical cancer screening uptake among the women.

\section{Reference:-}

1. Ferlay J, Soerjomataram I, Ervik M, Dikshit R, Eser S, Mathers C, et al . Comprehensive cervical cancer control: World Health Organization [WHO] 2013; IARC Cancer Base No. 11 [Internet]. Lyon, France: International Agency for Research on Cancer. Available from http://globocan.iarc.fr

2. Bray F, Ren JS, Masuyer E, Ferlay J .Global estimates of cancer prevalence for 27 sites in the adult population in2008. IntCancer, 2013;132(5):1133-1145. http://dx.doi.org/10.1002/ijc.27711 PMID:22752881.

3. WHO/ICO. Summary report on HPV and cervical cancer statistics in Ethiopia. 2015; Available from: http://www.hpvcentre.net/statistics/reports/ETH.pdf. Accessed June 22, 2015.

4. Bruni L, Barrionuevo-Rosas L, Albero G, Aldea M, Serrano B, Valencia S, et al. ICO Information Centre on HPV and Cancer (HPV Information Centre). Human Papillomavirus and Related Diseases in Ethiopia. Summary Report 2014; 12: 18. www.hpvcentre.net.

5. Hamad HM: Cancer initiatives in Sudan. Ann Oncol 2006, 17 Suppl 8:viii32-viii36.

6. Yusufu LMD: Early diagnosis of breast cancer. Ann Afr Med 2004, 3(2):95.

7. Anim JT: Breast cancer in sub-Saharan African women. Afr J Med MedSci 1993, 22(1):5-10.

8. Cracchiolo B. and Leitao M. Jr. Update on cervical cancer. Health Link 2006; 4 pages. 
9. Gharoro EP. And Ikeanyi EN. An appraisal of the level of awareness and utilization of the Pap smear as a cervical cancer screening test among female health workers in a tertiary health institution. International Journal of Gynecology Cancer 2006; 16: 1063-1068

10. Brinton LA, Herrero R, Reeves WC, et al. Risk factors for cervical cancer by histology. GynecolOncol. 1993;51:301-306

11. Munoz N, Bosch F \& de Sanjose S. Epidemiologic classification of human papillomavirus types associated with cervical cancer. New England Journal of Medicine 2003;348:518-527.

12. Clifford G, Smith J, Plummer M, Munoz N \&Franceschi S. Human papillomavirus types in invasive cervical cancer worldwide: a meta-analysis. British Journal of Cancer 2003; 88:63-73.

13. Clifford G et al. Vaccine 2006;24(S3):26-34). 